\title{
A Comparison between Anodizing and EBSD Techniques for Primary Particle Size Measurement
}

\author{
Shahrooz Nafisi ${ }^{1,2,3, *}$, Anthony Roccisano ${ }^{1}$ (D), Reza Ghomashchi ${ }^{1}$ and George Vander Voort ${ }^{4}$ \\ 1 School of Mechanical Engineering, The University of Adelaide, Adelaide, SA 5005, Australia; \\ a.roccisano@adelaide.edu.au (A.R.); reza.ghomashchi@adelaide.edu.au (R.G.) \\ 2 Department of Chemical and Materials Engineering, University of Alberta, Edmonton, AB T6G 1H9, Canada \\ 3 Consolidated Metco, Vancouver, WA 98661, USA \\ 4 Consultant-Struers Inc., Wadsworth, IL 60083, USA; george@georgevandervoort.com \\ * Correspondence: shahrooznafisi@gmail.com
}

Received: 26 March 2019; Accepted: 24 April 2019; Published: 27 April 2019

check for updates

\begin{abstract}
Proper understanding and knowledge of primary particle or grain size is of paramount importance in manufacturing processes as it directly affects various properties including mechanical behavior. Application of optical microscopy coupled with etching techniques has been used conventionally and in conjunction with color metallography (polarized microscopy) has been the preferred method for grain size measurement. An advanced technique as an alternative to light microscopy is using electron backscatter diffraction (EBSD). A comparison is made between these two techniques using Al-7Si alloy produced with various casting techniques to highlight the cost and time of the sample preparation and analysis for both techniques. Results showed that color metallography is certainly a faster technique with great accuracy and a much cheaper alternative in comparison with EBSD.
\end{abstract}

Keywords: polarized light microscopy; anodic etching; EBSD; grain; globule; Al-Si alloy; semi-solid metal processing; EMS; thixocasting

\section{Introduction}

Grain size plays an important role on the properties of metallic materials. Normally, the structure is observed on the plane of the polished surface using optical microscopy which is a two-dimensional (2D) measurement. The $2 \mathrm{D}$ analysis is not a complete representative of the $3 \mathrm{D}$ structure and in some instances may lead to a biased conclusion. However, it is the current practice for microstructural characterization and therefore there is an urge to ensure the procedure is as effective and accurate as possible. An example is shown in Figure 1 highlighting the deficiency of $2 \mathrm{D}$ analysis. The secondary dendritic branches are treated as individual and isolated particles during automatic image analysis processing [1]. 


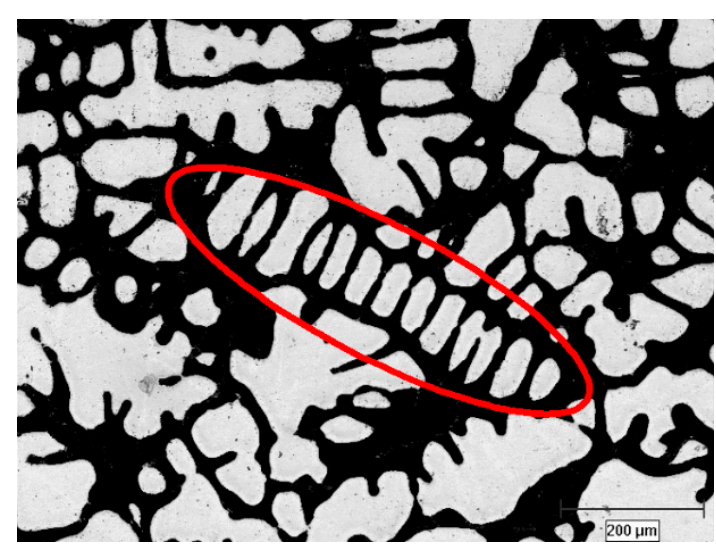

(a)

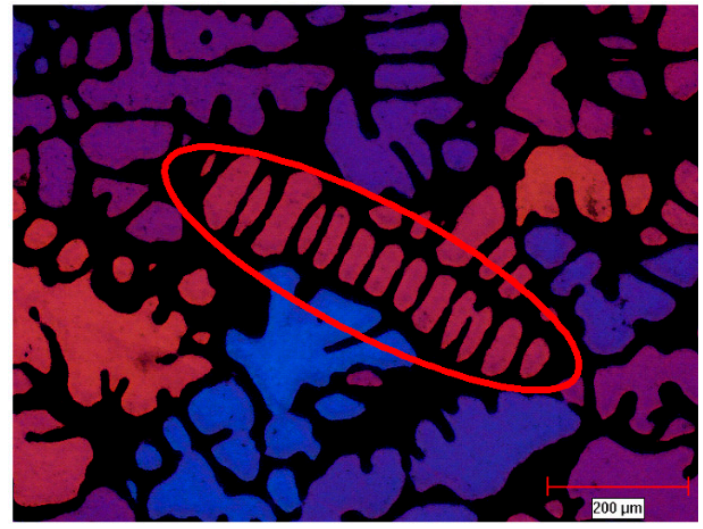

(b)

Figure 1. Branches of dendrites, A356 alloy, quenched from $598^{\circ} \mathrm{C}$ [1]: (a) bright field, and (b) polarized light image with sensitive tint plate, polished and anodized with Barker's reagent.

Various techniques have been used to overcome this inadequacy including advanced serial sectioning [2,3], X-ray tomography [4,5], and analysis of crystallographic orientations of the particles by electron backscatter diffraction (EBSD) technique (either 2D or 3D) [6,7]. The competing issues in using any of the aforementioned methods are the required equipment, the operator's skill and the analysis time which are eventually interpreted in terms of the cost of these methods. This is the theme of the current report; the accuracy, the cost (equipment), and time of two widely used methods of "anodic etching-polarized light microscopy" and EBSD in the analysis of semi solid metal (SSM) processed Al-Si alloy structure. The distinction between the individual grains and particles is important for SSM processes as it not only verifies the effectiveness of SSM process but also greatly affects the finished SSM parts mechanical properties.

Anodic oxidation, or anodizing, is an electrolytic process for depositing an oxide film on the metal surface epitaxial to the underlying grain structure. It is similar in nature to heat tinting or tint etching where an interference film is produced on the surface of metals. In this method, the sample is placed in the anodizing solution as the anode connected to a stainless steel or graphite plate or bar acting as the cathode. The resulting interference film colors when viewed under a polarizing light are a function of the anodic film thickness. The thickness, however, depends on the anodizing voltage, the anodizing solution composition, and the composition and/or structures of the phases present in the specimens and anodizing time. There are plenty of reports in open literature noting that certain etchants for Body Centered Cubic (BCC) and Face Centered Cubic (FCC) metals produce an interference film on the grain which results in grain contrast effect in bright field light microscopy. When viewed in polarized light, it yields color images that can be further enhanced by adding a sensitive tint plate [8,9].

EBSD is a technique that provides crystallographic information by analyzing crystalline samples in the scanning electron microscope (SEM). In EBSD, a stationary electron beam strikes a 70 degrees tilted sample and the diffracted electrons form a pattern on a fluorescent screen. The diffraction pattern is unique to the crystal structure and crystal orientation of the sample region from which it was generated. Diffraction patterns are used to measure the crystal orientation, grain boundary misorientations, discriminate between different materials, and to provide useful information about local crystalline perfection. By scanning in a grid across a polycrystalline sample and measuring the crystal orientation at each point, the resulting map will reveal the constituent grain morphology, orientations, and boundaries. In addition, the data shows the preferred crystal orientations (texture) present within the material [10,11].

Color metallography techniques have been developed for many metals and alloys, but they have not been utilized widely by metallographers, despite their obvious benefits. Color etchants are usually phase-specific and they will fully reveal the grain structure or specific second-phase constituents. Some, 
like Barker's anodizing solution, produce results that can only be observed using cross polarized light. Coloration in all cases, if weak, can be enhance by adding a sensitive tint filter (sometimes called a lambda plate). The coloration is due to variations in the crystallographic orientation of the grains or particles. Black and white etchants cannot reveal such differences. EBSD is commonly used to reveal crystallographic orientations between grains and phases, but the process requires an SEM equipped with an EBSD system. Coarser step sizes between diffraction patterns reduce the precision of the method, although it shortens the scan time. Specimen preparation for EBSD is much more challenging for most laboratories, and more time consuming. All preparation-induced damage must be removed to get high-quality EBSD grain maps, and the specimen surfaces must remain perfectly flat $[12,13]$. So, the use of color metallography by anodizing $\mathrm{Al}$ and its alloys, followed by examination using polarized light and a sensitive tint filter, is much faster, easier, and less expensive than EBSD.

This article attempts to highlight the effectiveness of employing polarized light microscopy in conjunction with anodizing, in revealing the individual grains or primary particles in SSM processed Al-Si alloy. The distribution of grains and particles are then compared with the grain size obtained from EBSD technique to emphasize the simplicity and low cost of color metallography. As a result of such practice, it was managed to identify the critical degrees of misorientation as the required criterion to differentiate between grains and subgrains in SSM processed alloys when using EBSD, which in its own right is an important finding by itself.

\section{Materials and Methods}

Binary Al-7\% Si alloys (6.7-6.9\% Si, $0.8-0.81 \% \mathrm{Fe}$ ) were prepared in an electric resistance furnace. Two different molds were used; for higher cooling rate, a copper mold with a water-cooled jacket was used and for the lower cooling rate, $\mathrm{a} \mathrm{CO}_{2}$ bonded silica-sand mold was employed. Ingots were 76-mm in diameter and 300-mm long. The entire configuration was placed in an electromagnetic stirring machine (EMS). The frequency was set to $50 \mathrm{~Hz}$ and the current was 100 and $30 \mathrm{~A}$ for copper and sand molds, respectively (the application of magnetic field was stopped when the alloy temperature in the molds reached $400{ }^{\circ} \mathrm{C}$ on cooling). The application of different currents was intended to ensure that the applied magnetic force to stir the molten alloy is almost the same for both the sand and copper molds. Experimental details are explained in further detail elsewhere [14]. Pouring temperature was changed between 630 and $690^{\circ} \mathrm{C}$. The cooling rate in the copper and sand molds for the conventional ingot (with no stirring) was about 4.8 and $3.3^{\circ} \mathrm{C} / \mathrm{s}$, respectively (the cooling rates were calculated in the liquid state above the liquidus temperature).

For thixocast trials (reheating to semi-solid region), samples were cut from the transverse sections (200 $\mathrm{mm}$ from the bottom of EMS billets), in areas between the billet center and wall, and were reheated in a single coil $5 \mathrm{~kW}$ induction furnace operating at $80 \mathrm{kHz}$. Samples were placed vertically on an insulator plate. Temperature variation during the tests was monitored by attaching thermocouples to both the billet center and the wall. The induction furnace was controlled by the central thermocouple and the wall thermocouple was used to establish if there is any transverse temperature gradient within the billet. The reheating cycle included 2-3 min of heating up to $583 \pm 3{ }^{\circ} \mathrm{C}$ and $10 \mathrm{~min}$ holding time at this temperature before water quenching (at the selected holding temperature of $583 \pm 3{ }^{\circ} \mathrm{C}$, there is about $38-40 \%$ fraction of solid alloy according to ThermoCalc calculations). For EMS cast samples, the metallographic specimens were cut transversely at 200-mm from the bottom of the billets, mounted in Bakelite, ground, and polished conventionally down to $0.05 \mu \mathrm{m}$ colloidal silica to develop high quality EBSD (Struers, Willich, Germany) maps. Thixocast samples were prepared simply by cutting a transverse section of the quenched samples.

EBSD analysis was undertaken with an FEI Inspect F50 Field Emission Gun (FEG) Scanning Electron Microscope (SEM) with an EDAX Hikari detector. In each specimen at least four regions were located using a microhardness indent and were scanned through EBSD. At least four regions per specimen were scanned at 200X magnification, with a scan frame of $800 \times 800 \mu \mathrm{m}^{2}$ and a step size of $1.5 \mu \mathrm{m}$ taking approximately $45 \mathrm{~min}$ to scan. In addition, each specimen had a region scanned at $100 \times$ 
magnification with a scan frame of $1600 \times 1600 \mu \mathrm{m}^{2}$ and a step size of $2 \mu \mathrm{m}^{2}$ taking approximately $90 \mathrm{~min}$ to scan. After the EBSD analysis, the samples were anodized. Samples were immersed in a solution of Barkers reagent (1.8\% fluoroboric acid in water) and anodized until a color shift was observed under polarized light microscopy ( $20 \mathrm{~V}$ direct current, $4 \mathrm{~min}$ ). Polarized light microscopy was undertaken on a Zeiss AXIO Imager.M2m (Carl Zeiss Microscopy, Jena, Germany) equipped with reflected light polarizer and, rotatable analyzer with lambda plate. Regions that were scanned with EBSD were subsequently viewed under polarized light microscopy and the grain boundary properties determined under each were compared.

The acquisition time for color metallography and EBSD is provided in Table 1 indicating the approximate time spent acquiring grain boundary data. Sample preparation time is typically $30 \mathrm{~min}$ longer for EBSD samples due to the increased colloidal silica polishing time required to produce strong patterns and the stricter cleaning regime required to produce good scans. The EBSD acquisition time is heavily dependent upon the available equipment and the resolution of the scan with the newer detectors offering shorter scan times for the same resolution, however, there are extended waiting periods in all models from pumping and venting the chamber as well as locating the scan area. In addition to the above time allocation to acquire the desired outcome, it is important to point out that the level of skill to run the EBSD is far more demanding than the one for anodizing and optical microscopy. On top of that, the capital investment is nowhere comparable.

Table 1. Time consumption acquiring grain boundary data through color metallography and electron backscatter diffraction (EBSD).

\begin{tabular}{ccc}
\hline Process Parameter & Color Metallography (minutes) & EBSD (minutes) \\
\hline Sample Preparation & 20 & 50 \\
Anodizing & 10 (per sample) & - \\
Optical Microscopy & 10 (per sample) & - \\
EBSD & - & 75 (per scan) \\
Post-processing of Results & - & 15 (per scan) \\
Total & 40 & 140 \\
\hline
\end{tabular}

\section{Results and Discussions}

Generally, aluminum hypoeutectic alloys consist of two main constituents, primary $\alpha$-Al particles and eutectic mixture of $\alpha-\mathrm{Al}$ and $\mathrm{Si}$ (in this specific alloy, due to the extra addition of iron, some $\beta$-iron intermetallics were formed). Effects of different cooling rates on the silicon and iron flake sizes and distribution in the as-cast EMS samples are shown in Figure 2. Lower cooling rate in the sand mold shows larger dendrites comparing to that of the copper mold specimens. Dendrite size had a great difference since the cooling rate is higher in the copper mold (Figure 2c,d). At higher magnifications, a great difference could be seen in the size of the silicon eutectic flakes and $\beta$-iron intermetallics. By pouring the alloy in the copper mold, i.e., with a higher cooling rate, silicon and $\beta$-iron intermetallics got thinner and shorter (compare Figure $2 b$ with Figure 2d). 


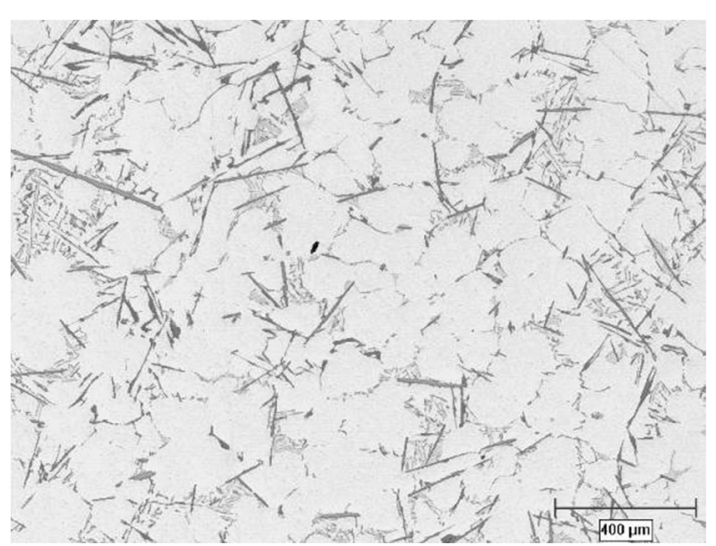

(a)

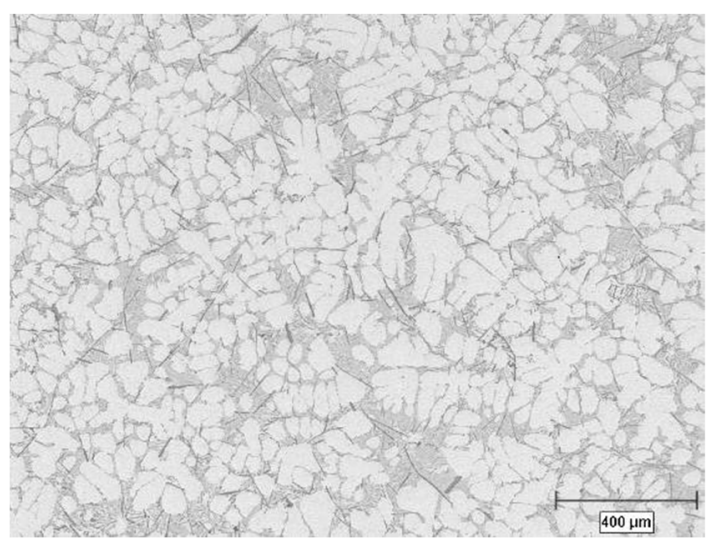

(c)

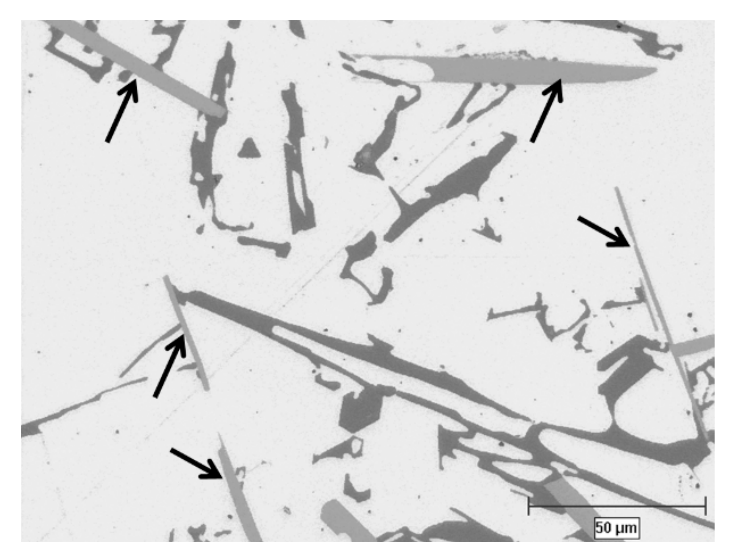

(b)

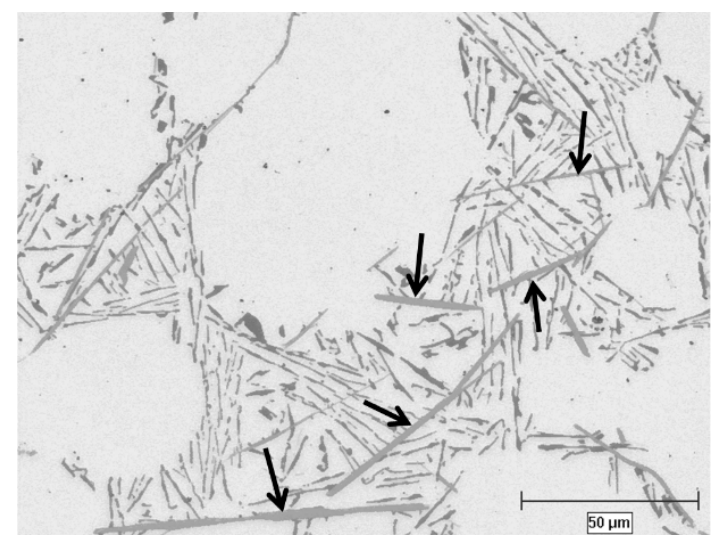

(d)

Figure 2. Optical micrographs showing the effect of cooling rate on the microstructure of as-cast magnetic stirring machine (EMS) billets: $(\mathbf{a}, \mathbf{b})$ sand mold and $(\mathbf{c}, \mathbf{d})$ copper mold, pouring temperature $690^{\circ} \mathrm{C}$, etched with $0.5 \%$ Hydrofluoric acid (HF) (arrows show some of the iron-intermetallics). Scale bar is $400 \mu \mathrm{m}$ for (a) and (c), $50 \mu \mathrm{m}$ for (b) and (d).

During isothermal holding, the eutectic mixture was re-melted while the primary $\alpha$-Al phase was coarsened. There was also a driving force towards reduction of interfacial area which results in globularization of the primary $\alpha$-Al particles (Figure 3).

In order to discuss the correlation between EBSD and anodizing, it is better to examine the thixocast structure first which, due to the better clarity of individual particles, makes comparison much easier and convenient than for the EMS which the particles sometimes are intertwined.

Figure 4 shows an example of color metallography and EBSD of the same area of the sample cast in copper mold at $630{ }^{\circ} \mathrm{C}$ and isothermally held at $\sim 583{ }^{\circ} \mathrm{C}$ for $10 \mathrm{~min}$. As discussed earlier, by isothermal holding, primary $\alpha-\mathrm{Al}$ particles became spherical and some of the primary particles possibly sintered together. The colors in the polarized light micrograph, Figure $4 \mathrm{a}$, were indications of different orientations of the primary particles while a similar color indicates the same nucleation and growth pattern. In this specific example, particles $\mathrm{K}-\mathrm{L}, \mathrm{J}-\mathrm{M}, \mathrm{M}-\mathrm{N}, \mathrm{O}-\mathrm{P}, \mathrm{T}-\mathrm{X}, \mathrm{X}-\mathrm{Y}$, and $\mathrm{Z}-\mathrm{O}$ possibly sintered, i.e., two or more isolated solid particles joined and formed a pseudo cluster that is associated mainly to the stabilized contact during post heat treatment processing [1]. In the semi-solid science, this phenomenon is defined as "agglomeration" [15-17] where primary particles come into contact and possibly sinter together to form agglomerates. 


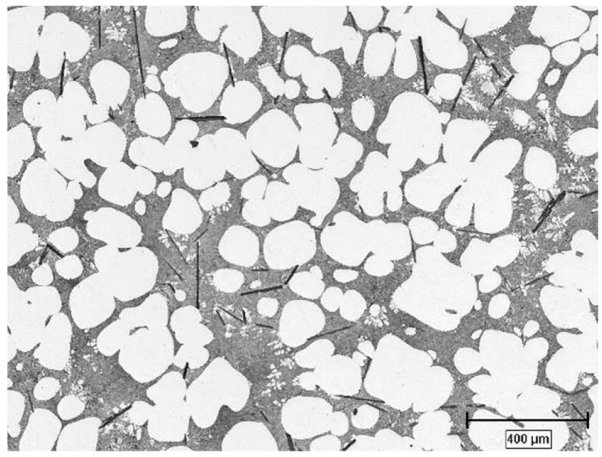

(a)

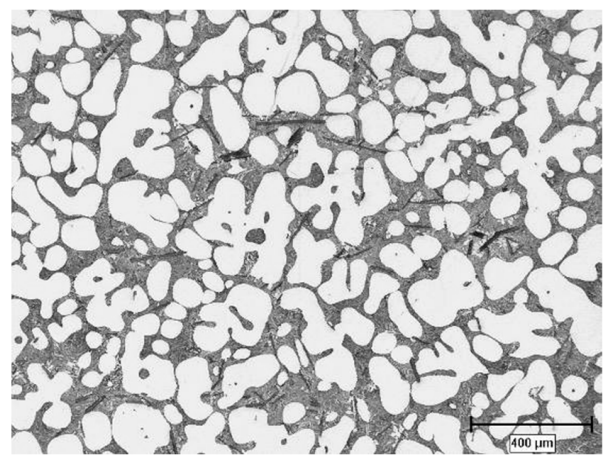

(c)

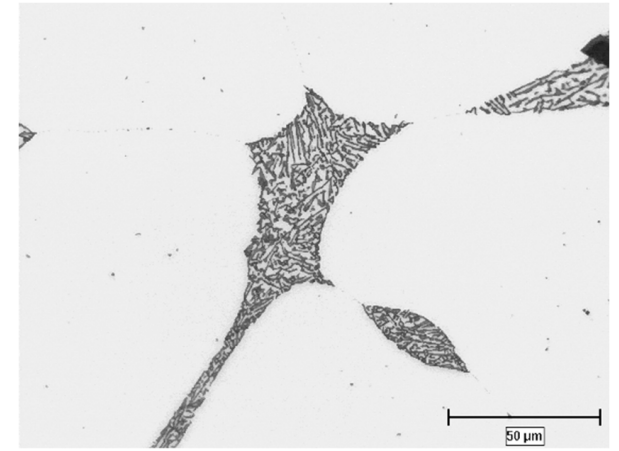

(b)

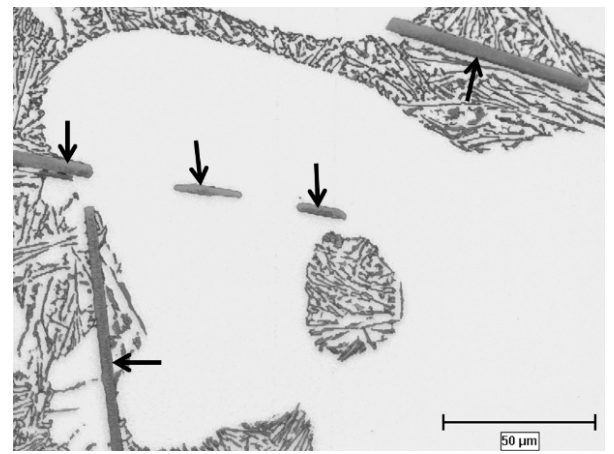

(d)

Figure 3. Optical micrographs showing the effect of isothermal holding on the microstructure of thixocast samples: (a,b) sand mold and (c,d) copper mold, pouring temperature $690{ }^{\circ} \mathrm{C}$, etched with $0.5 \% \mathrm{HF}$ (arrows show some of the iron-intermetallics). Scale bar is $400 \mu \mathrm{m}$ for $(\mathbf{a}, \mathbf{c}), 50 \mu \mathrm{m}$ for $(\mathbf{b}, \mathbf{d})$.

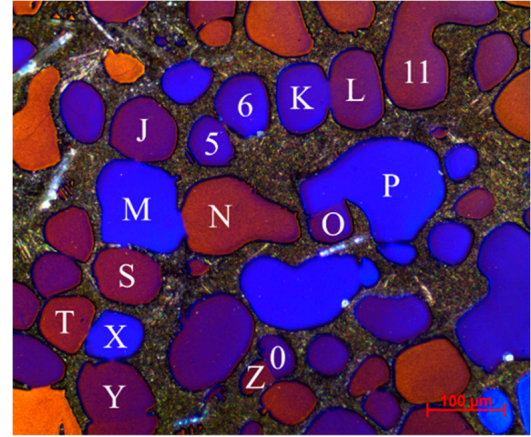

(a)

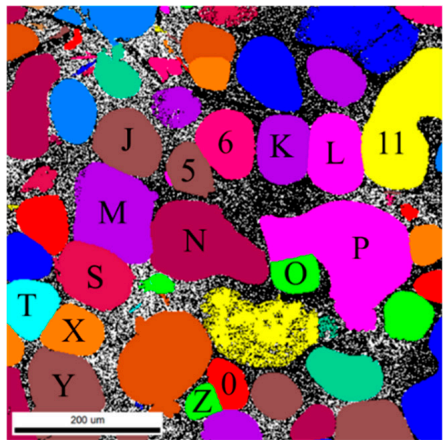

(c)
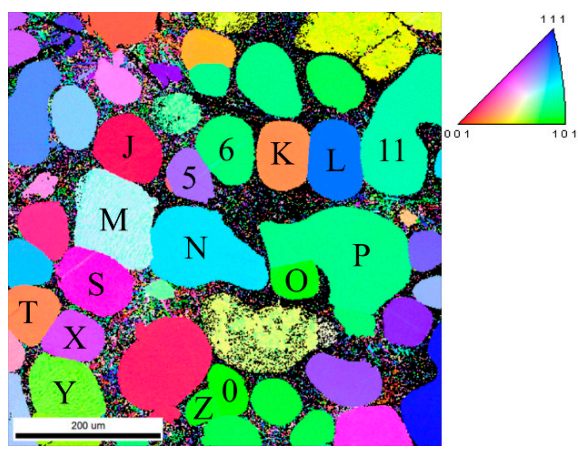

(b)

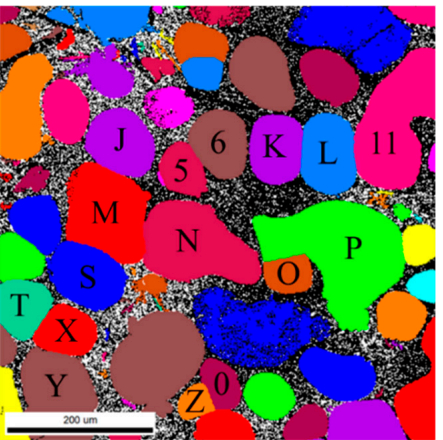

(d)

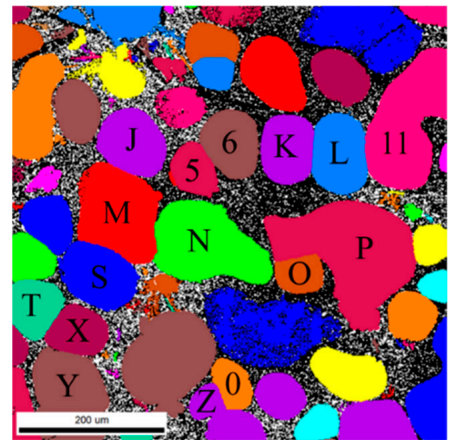

(e)

Figure 4. Thixocast sample, copper mold, poured at $630{ }^{\circ} \mathrm{C}$; (a) polarized light image with sensitive tint plate, polished and anodized with Barker's reagent, (b) inverse pole figure (IPF) map, (c) $5^{\circ}$ grain map, (d) $10^{\circ}$ grain map, (e) $15^{\circ}$ grain map. 
Table 2 presents information such as misorientation between particles, and whether they are detectable as individual grains when the grain boundary misorientation criteria were set at five, 10 , and 15 degrees. For example, particles $\mathrm{K}$ and $\mathrm{L}$ had a misorientation of 55.6 degree specifying that these two are indeed two separate grains. Changing the critical misorientation angle from five to 10 and then 15 (Figure 4c-e) did not change the grain map and proved that these two particles are two individual grains and polarized image confirmed the fact. The investigated areas in all samples were analyzed using the same methodology.

Table 2. EBSD data for thixocast sample, copper mold, poured at $630{ }^{\circ} \mathrm{C}(\mathrm{Y}, \mathrm{Yes} ; \mathrm{N}, \mathrm{No})$.

\begin{tabular}{cccccc}
\hline $\begin{array}{c}\text { Grain } \\
\text { Boundary }\end{array}$ & Misorientation & $\begin{array}{c}\text { EBSD 5 }^{\circ} \\
\text { Misorientation }\end{array}$ & $\begin{array}{c}\text { EBSD 10 }^{\circ} \\
\text { Misorientation }\end{array}$ & $\begin{array}{c}\text { EBSD 15 }^{\circ} \\
\text { Misorientation }\end{array}$ & $\begin{array}{c}\text { Color } \\
\text { Metallography }\end{array}$ \\
\hline KL & 55.6 & $\mathrm{Y}$ & $\mathrm{Y}$ & $\mathrm{Y}$ & $\mathrm{Y}$ \\
JM & 32.7 & $\mathrm{Y}$ & $\mathrm{Y}$ & $\mathrm{Y}$ & $\mathrm{Y}$ \\
MN & 55.6 & $\mathrm{Y}$ & $\mathrm{Y}$ & $\mathrm{Y}$ & $\mathrm{Y}$ \\
MS & 42.3 & $\mathrm{Y}$ & $\mathrm{Y}$ & $\mathrm{Y}$ & $\mathrm{Y}$ \\
$\mathrm{TX}$ & 29.8 & $\mathrm{Y}$ & $\mathrm{Y}$ & $\mathrm{Y}$ & $\mathrm{Y}$ \\
XY & 43 & $\mathrm{Y}$ & $\mathrm{Y}$ & $\mathrm{Y}$ & $\mathrm{Y}$ \\
OP & 59.3 & $\mathrm{Y}$ & $\mathrm{Y}$ & $\mathrm{Y}$ & $\mathrm{Y}$ \\
Z0 & 58.7 & $\mathrm{Y}$ & $\mathrm{Y}$ & $\mathrm{Y}$ & \\
L 11 & 38.3 & $\mathrm{Y}$ & $\mathrm{Y}$ & & $\mathrm{Y}$ \\
\hline
\end{tabular}

Figure 5 presents another example of color metallography and EBSD of the sample cast in copper mold at $690{ }^{\circ} \mathrm{C}$ and isothermally held at $\sim 583{ }^{\circ} \mathrm{C}$ for $10 \mathrm{~min}$. In comparison to Figure $4 \mathrm{a}$, the $\alpha-\mathrm{Al}$ particles in Figure $5 \mathrm{a}$ are larger and present fewer colors, meaning that fewer individual particles of varying crystal orientation formed within this process. This is due to the fact that the higher pouring temperature resulted in fewer nucleation sites and more dendritic structure. This subject was explained in another publication [14].

Some of the particles in Figure 5 belong to one primary dendrite as they show the same color contrast. This is regardless of changing the misorientation angle criteria. An example is particles 1, 2, 3, and 4 . By increasing the grain misorientation criterion from 5 to 10 or even 15-degrees, particles 1-4 still have the same color contrast. However, by increasing the misorientation to 10 degrees, particles $\mathrm{E}$ and E1 showed similar color to particles 1-4 (Figure 5d,e). This indicates similar origin and disintegration mechanism for all of the adjacent particles of similar color contrast. The same rationale is applicable for particles C1-C3 meaning that they are originated from the same dendrite. C1-C3 appear as three distinct particles when the misorientation is five degrees. This may indicate these sub grain particles are separated from each other by five degree or less. When the misorientation criterion increases to 10 or 15 degrees, they show the same color which means they were originated from the same dendrite (considering that the sample was electromagnetically stirred and dendrites cramped and/or broken during this process, however they all have their origin in one dendrite). In other words, what it is being said here is the fact that although the particles are detected as individual particles with clear grain boundaries, they may be connected from underneath the plane of polish or broken down by stirring action during semi-solid processing. Nonetheless, the most important finding here is the similarity of polarized light microscopy of anodized specimen with those of EBSD characterization and grain mapping, particularly when a critical misorientation angle of 10 degrees is implemented. Table 3 shows additional EBSD information on some specific particles and whether they are detectable as individual grains in color metallography. 


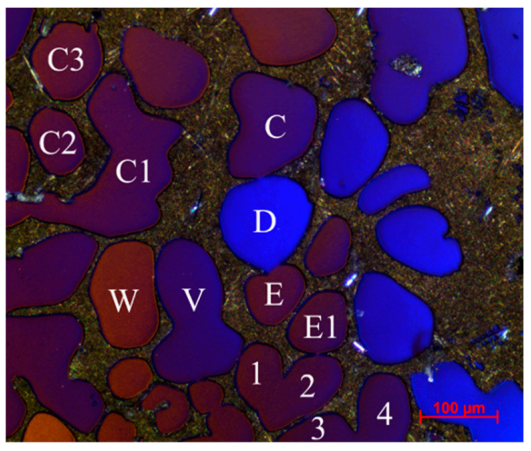

(a)

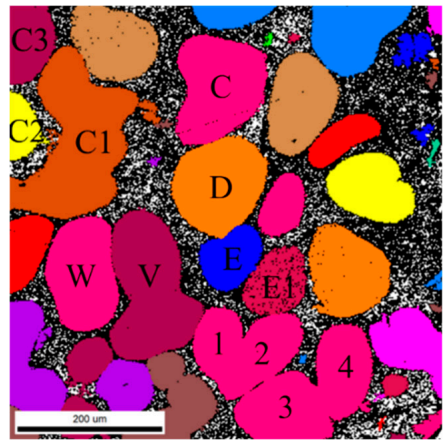

(c)

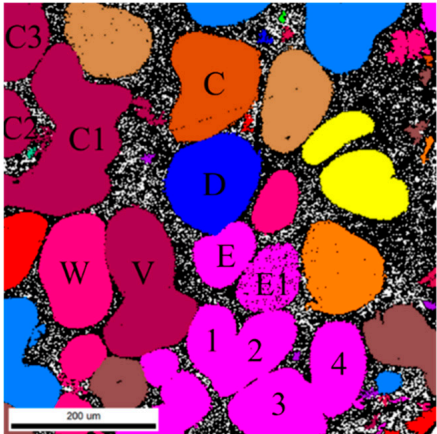

(d)

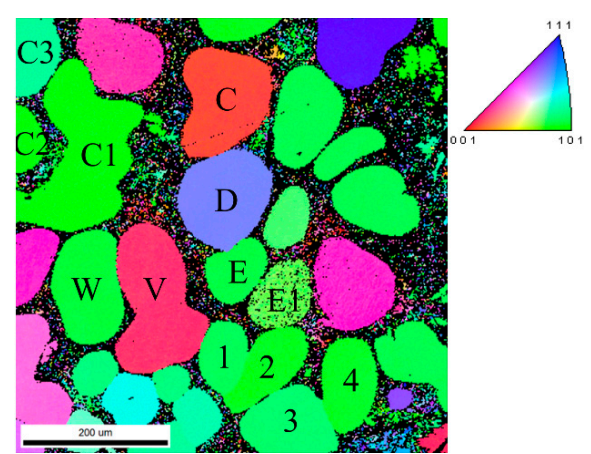

(b)

Figure 5. Thixocast sample, copper mold, poured at $690^{\circ} \mathrm{C}$; (a) polarized light image with sensitive tint plate, polished and anodized with Barker's reagent, (b) IPF map, (c) $5^{\circ}$ grain map, (d) $10^{\circ}$ grain map, (e) $15^{\circ}$ grain map.

Table 3. EBSD data for thixocast sample, copper mold, poured at $690{ }^{\circ} \mathrm{C}$ (Y, Yes; N, No).

\begin{tabular}{cccccc}
\hline $\begin{array}{c}\text { Grain } \\
\text { Boundary }\end{array}$ & Misorientation & $\begin{array}{c}\text { EBSD 5 }^{\circ} \\
\text { Misorientation }\end{array}$ & $\begin{array}{c}\text { EBSD 10 }^{\circ} \\
\text { Misorientation }\end{array}$ & $\begin{array}{c}\text { EBSD 15 }^{\circ} \\
\text { Misorientation }\end{array}$ & $\begin{array}{c}\text { Color } \\
\text { Metallography }\end{array}$ \\
\hline CD & 58 & $\mathrm{Y}$ & $\mathrm{Y}$ & $\mathrm{Y}$ & $\mathrm{Y}$ \\
$\mathrm{DE}$ & 51.6 & $\mathrm{Y}$ & $\mathrm{Y}$ & $\mathrm{Y}$ & $\mathrm{Y}$ \\
$\mathrm{VW}$ & 38.4 & $\mathrm{Y}$ & $\mathrm{Y}$ & $\mathrm{Y}$ & $\mathrm{Y}$ \\
12 & 2.4 & $\mathrm{~N}$ & $\mathrm{~N}$ & $\mathrm{~N}$ & $\mathrm{~N}$ \\
34 & 4.2 & $\mathrm{~N}$ & $\mathrm{~N}$ & $\mathrm{~N}$ & $\mathrm{~N}$ \\
\hline
\end{tabular}

Representatives of as-cast EMS sand billets are shown in Figures 6 and 7. The application of electromagnetic stirring results in forced convection of the bulk liquid which encourages dendrites fragmentation as well as dendrite arm root re-melting due to the thermal and solutal convection [1]. It is also important to consider that in contrast to the conventional casting, electromagnetic stirring of the melts with higher superheat results in more re-melting of the nuclei [18]. 


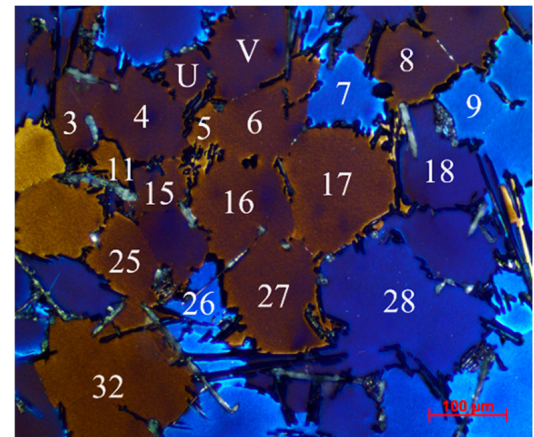

(a)

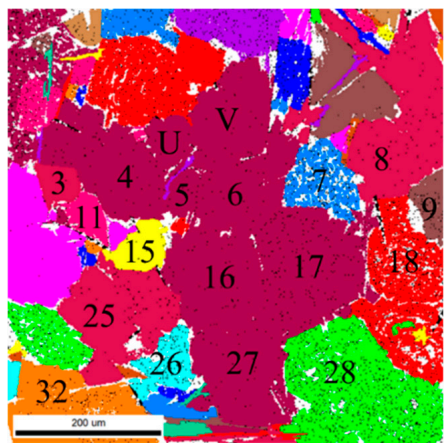

(c)

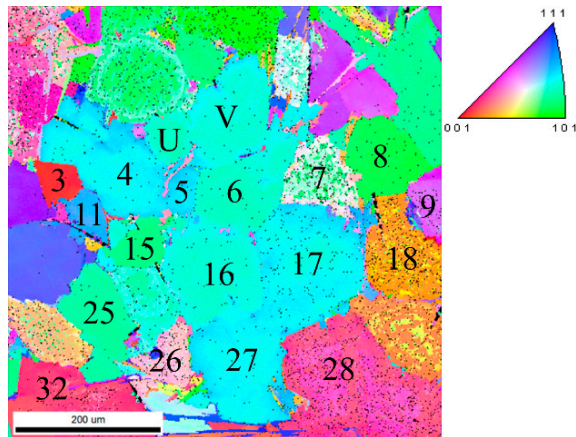

(b)

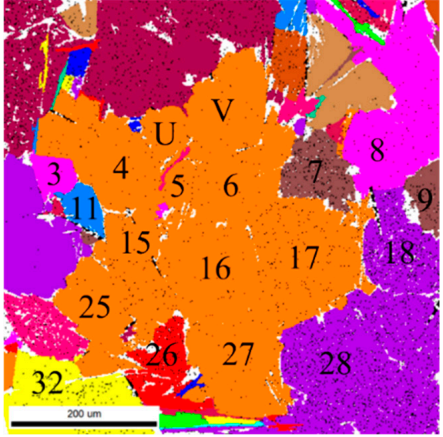

(d)

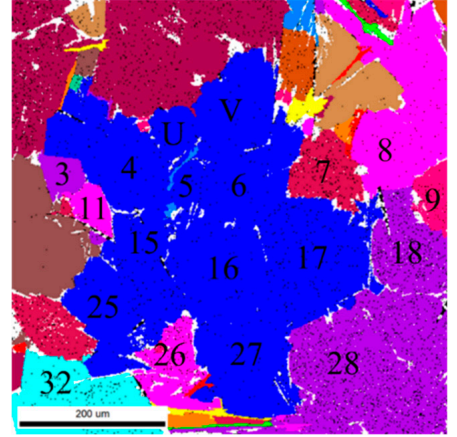

(e)

Figure 6. As-cast EMS billets, sand mold, poured at $630^{\circ} \mathrm{C}$; (a) polarized light image with sensitive tint plate, polished and anodized with Barker's reagent, (b) IPF map, (c) $5^{\circ}$ grain map, (d) $10^{\circ}$ grain map, (e) $15^{\circ}$ grain map.

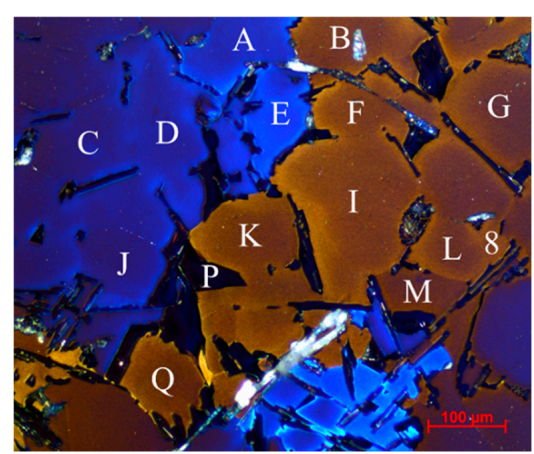

(a)

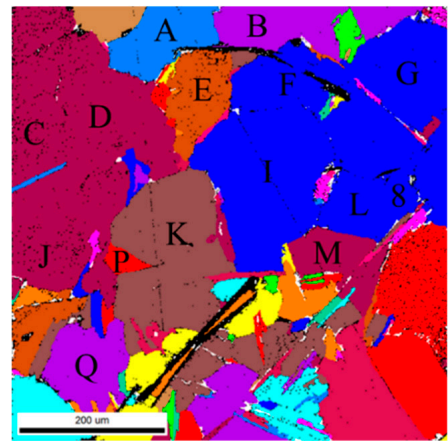

(c)

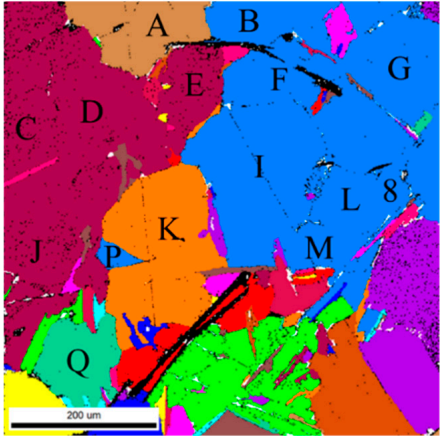

(d)

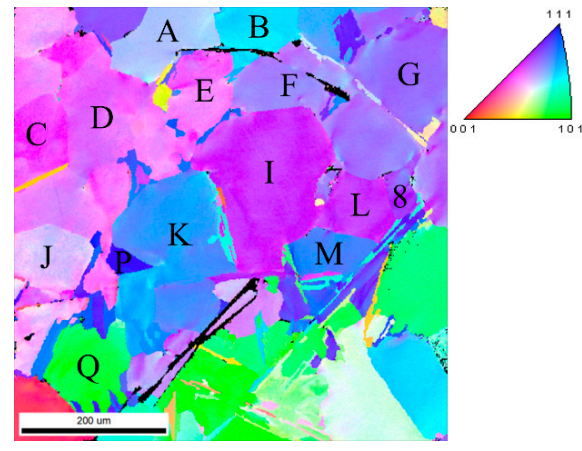

(b)

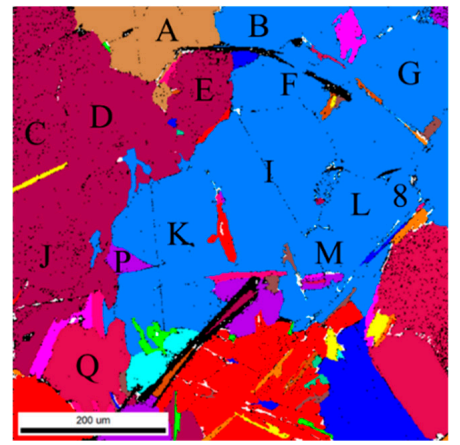

(e)

Figure 7. As-cast EMS billets, sand mold, poured at $690^{\circ} \mathrm{C}$; (a) polarized light image with sensitive tint plate, polished and anodized with Barker's reagent, (b) IPF map, (c) $5^{\circ}$ grain map, (d) $10^{\circ}$ grain map, (e) $15^{\circ}$ grain map. 
Quality of the colored images depends not only to the anodizing technique (e.g., solution, voltage, time, temperature which all were constant for these samples), but also to the alloying elements and manufacturing process. By isothermally holding the samples, the image quality and color differentiation improves (compare Figures 4-7).

As a result, detection of the individual grains in color metallography is a challenging task. For instance, in Figure 6, particles 3 and 4 are two different grains according to EBSD grain maps; however, polarized light microscopy is unable to detect the differences between the two grains (Figure 6a). By increasing the critical misorientation angle to 10 degrees, some particles such as $4-15,15-16,18-28$, and 16-25 present similar color in EBSD grain mapping. Table 4 provides additional information on the area presented in Figure 6.

Table 4. EBSD data for as-cast EMS billets, sand mold, poured at $630^{\circ} \mathrm{C}$ (Y, Yes; N, No).

\begin{tabular}{|c|c|c|c|c|c|}
\hline $\begin{array}{c}\text { Grain } \\
\text { Boundary }\end{array}$ & Misorientation & $\begin{array}{c}\text { EBSD }^{\circ} \\
\text { Misorientation }\end{array}$ & 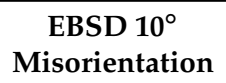 & 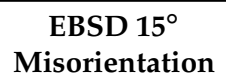 & $\begin{array}{c}\text { Color } \\
\text { Metallography }\end{array}$ \\
\hline UV & 2.9 & $\mathrm{~N}$ & $\mathrm{~N}$ & $\mathrm{~N}$ & $\mathrm{~N}$ \\
\hline $\mathrm{U} 4$ & 6.8 & $\mathrm{~N}$ & $\mathrm{~N}$ & $\mathrm{~N}$ & $\mathrm{~N}$ \\
\hline U5 & 8.4 & $\mathrm{~N}$ & $\mathrm{~N}$ & $\mathrm{~N}$ & $\mathrm{~N}$ \\
\hline V5 & 5.9 & $\mathrm{~N}$ & $\mathrm{~N}$ & $\mathrm{~N}$ & $\mathrm{~N}$ \\
\hline V6 & 3.8 & $\mathrm{~N}$ & $\mathrm{~N}$ & $\mathrm{~N}$ & $\mathrm{~N}$ \\
\hline 311 & 58.5 & $\mathrm{Y}$ & $\mathrm{Y}$ & $\mathrm{Y}$ & $\mathrm{Y}$ \\
\hline 34 & 55.8 & $\mathrm{Y}$ & $\mathrm{Y}$ & $\mathrm{Y}$ & $\mathrm{N}$ \\
\hline 45 & 10.2 & $\mathrm{~N}$ & $\mathrm{~N}$ & $\mathrm{~N}$ & $\mathrm{~N}$ \\
\hline 415 & 10.3 & $\mathrm{Y}$ & $\mathrm{N}$ & $\mathrm{N}$ & $\mathrm{N}$ \\
\hline 411 & 35.6 & Y & $\mathrm{Y}$ & Y & $\mathrm{Y}$ \\
\hline 56 & 5 & $\mathrm{~N}$ & $\mathrm{~N}$ & $\mathrm{~N}$ & $\mathrm{~N}$ \\
\hline 515 & 12.3 & $\mathrm{Y}$ & $\mathrm{N}$ & $\mathrm{N}$ & $\mathrm{N}$ \\
\hline 516 & 3.4 & $\mathrm{~N}$ & $\mathrm{~N}$ & $\mathrm{~N}$ & $\mathrm{~N}$ \\
\hline 67 & 55.3 & $\mathrm{Y}$ & $\mathrm{Y}$ & $\mathrm{Y}$ & $\mathrm{Y}$ \\
\hline 616 & 2.3 & $\mathrm{~N}$ & $\mathrm{~N}$ & $\mathrm{~N}$ & $\mathrm{~N}$ \\
\hline 617 & 8.3 & $\mathrm{~N}$ & $\mathrm{~N}$ & $\mathrm{~N}$ & $\mathrm{~N}$ \\
\hline 78 & 50.9 & $\mathrm{Y}$ & $\mathrm{Y}$ & $\mathrm{Y}$ & $\mathrm{Y}$ \\
\hline 717 & 55.8 & $\mathrm{Y}$ & $\mathrm{Y}$ & $\mathrm{Y}$ & $\mathrm{Y}$ \\
\hline 89 & 53 & $\mathrm{Y}$ & $\mathrm{Y}$ & $\mathrm{Y}$ & $\mathrm{Y}$ \\
\hline 818 & 43.9 & $\mathrm{Y}$ & $\mathrm{Y}$ & $\mathrm{Y}$ & $\mathrm{Y}$ \\
\hline 918 & 60 & $\mathrm{Y}$ & $\mathrm{Y}$ & $\mathrm{Y}$ & $\mathrm{Y}$ \\
\hline 1115 & 28.2 & $\mathrm{Y}$ & $\mathrm{Y}$ & $\mathrm{Y}$ & $\mathrm{Y}$ \\
\hline 1516 & 8.4 & Y & $\mathrm{N}$ & $\mathrm{N}$ & $\mathrm{N}$ \\
\hline 1525 & 4 & $\mathrm{Y}$ & $\mathrm{N}$ & $\mathrm{N}$ & $\mathrm{N}$ \\
\hline 1617 & 6.5 & $\mathrm{~N}$ & $\mathrm{~N}$ & $\mathrm{~N}$ & $\mathrm{~N}$ \\
\hline 1627 & 3.7 & $\mathrm{~N}$ & $\mathrm{~N}$ & $\mathrm{~N}$ & $\mathrm{~N}$ \\
\hline 1626 & 41.3 & $\mathrm{Y}$ & Y & Y & Y \\
\hline 1718 & 44.8 & $\mathrm{Y}$ & $\mathrm{Y}$ & $\mathrm{Y}$ & $\mathrm{Y}$ \\
\hline 1728 & 51 & $\mathrm{Y}$ & $\mathrm{Y}$ & $\mathrm{Y}$ & $\mathrm{Y}$ \\
\hline 1828 & 14.7 & $\mathrm{Y}$ & $\mathrm{N}$ & $\mathrm{N}$ & $\mathrm{N}$ \\
\hline 2526 & 40.9 & $\mathrm{Y}$ & $\mathrm{Y}$ & $\mathrm{Y}$ & $\mathrm{Y}$ \\
\hline 2627 & 41.8 & $\mathrm{Y}$ & $\mathrm{Y}$ & $\mathrm{Y}$ & Y \\
\hline 2728 & 53.2 & Y & $\mathrm{Y}$ & $\mathrm{Y}$ & $\mathrm{Y}$ \\
\hline
\end{tabular}

The same is applicable in Figure 7 for as-cast EMS billets, sand mold, poured at $690{ }^{\circ} \mathrm{C}$. Particles A and $\mathrm{E}, \mathrm{A}$ and $\mathrm{D}, \mathrm{K}$ and $\mathrm{Q}$ are different grains according to EBSD; however, polarized light microscopy is unable to detect the grains. By increasing the critical grain misorientation to 10 degrees, particles B-F, D-E, I-M, and M-L exhibit similar color (see Table 5), once more confirming that a 10-degree misorientation is an acceptable grain detection limit for EBSD technique (see Figure 6). 
Table 5. EBSD data for as-cast magnetic stirring machine (EMS) billets, sand mold, poured at $690{ }^{\circ} \mathrm{C}(\mathrm{Y}$, Yes; N, No).

\begin{tabular}{|c|c|c|c|c|c|}
\hline $\begin{array}{c}\text { Grain } \\
\text { Boundary }\end{array}$ & Misorientation & $\begin{array}{c}\text { EBSD }^{\circ} \\
\text { Misorientation }\end{array}$ & $\begin{array}{c}\text { EBSD } 10^{\circ} \\
\text { Misorientation }\end{array}$ & $\begin{array}{c}\text { EBSD 15 } \\
\text { Misorientation }\end{array}$ & $\begin{array}{c}\text { Color } \\
\text { Metallography }\end{array}$ \\
\hline $\mathrm{AB}$ & 34.1 & Y & $\mathrm{Y}$ & $\mathrm{Y}$ & $\mathrm{Y}$ \\
\hline $\mathrm{AE}$ & 53.4 & Y & $\mathrm{Y}$ & $\mathrm{Y}$ & $\mathrm{N}$ \\
\hline $\mathrm{AD}$ & 53.1 & Y & $\mathrm{Y}$ & $\mathrm{Y}$ & $\mathrm{N}$ \\
\hline $\mathrm{BF}$ & 21.7 & Y & $\mathrm{N}$ & $\mathrm{N}$ & $\mathrm{N}$ \\
\hline $\mathrm{BE}$ & 39.6 & Y & $\mathrm{Y}$ & $\mathrm{Y}$ & $\mathrm{Y}$ \\
\hline $\mathrm{CD}$ & 5.3 & $\mathrm{~N}$ & $\mathrm{~N}$ & $\mathrm{~N}$ & $\mathrm{~N}$ \\
\hline $\mathrm{DE}$ & 8.2 & $\mathrm{Y}$ & $\mathrm{N}$ & $\mathrm{N}$ & $\mathrm{N}$ \\
\hline DJ & 4.8 & $\mathrm{~N}$ & $\mathrm{~N}$ & $\mathrm{~N}$ & $\mathrm{~N}$ \\
\hline DK & 52.2 & $\mathrm{Y}$ & $\mathrm{Y}$ & $\mathrm{Y}$ & $\mathrm{Y}$ \\
\hline DI & 43.1 & $\mathrm{Y}$ & $\mathrm{Y}$ & $\mathrm{Y}$ & $\mathrm{Y}$ \\
\hline EI & 43.4 & $\mathrm{Y}$ & $\mathrm{Y}$ & $\mathrm{Y}$ & $\mathrm{Y}$ \\
\hline $\mathrm{EF}$ & 49.4 & $\mathrm{Y}$ & $\mathrm{Y}$ & $\mathrm{Y}$ & $\mathrm{Y}$ \\
\hline FG & 8.8 & $\mathrm{~N}$ & $\mathrm{~N}$ & $\mathrm{~N}$ & $\mathrm{~N}$ \\
\hline GL & 6.4 & $\mathrm{~N}$ & $\mathrm{~N}$ & $\mathrm{~N}$ & $\mathrm{~N}$ \\
\hline G8 & 10.3 & $\mathrm{~N}$ & $\mathrm{~N}$ & $\mathrm{~N}$ & $\mathrm{~N}$ \\
\hline IL & 3.9 & $\mathrm{~N}$ & $\mathrm{~N}$ & $\mathrm{~N}$ & $\mathrm{~N}$ \\
\hline IK & 15.2 & $\mathrm{Y}$ & $\mathrm{Y}$ & $\mathrm{N}$ & $\mathrm{N}$ \\
\hline IM & 14 & Y & $\mathrm{N}$ & $\mathrm{N}$ & $\mathrm{N}$ \\
\hline $\mathrm{KP}$ & 19.6 & $\mathrm{Y}$ & $\mathrm{Y}$ & $\mathrm{Y}$ & $\mathrm{Y}$ \\
\hline KQ & 36.2 & $\mathrm{Y}$ & $\mathrm{Y}$ & $\mathrm{Y}$ & $\mathrm{N}$ \\
\hline LM & 11.4 & $\mathrm{Y}$ & $\mathrm{N}$ & $\mathrm{N}$ & $\mathrm{N}$ \\
\hline L8 & 6.8 & $\mathrm{~N}$ & $\mathrm{~N}$ & $\mathrm{~N}$ & $\mathrm{~N}$ \\
\hline
\end{tabular}

Various areas were analyzed in these four samples and Figures 8 and 9 presents the comparison graphs. In these graphs, misorientations were categorized in different bins; each bin spans over 5-degree misorientation. To develop the graphs in Figures $8 \mathrm{a}$ and $9 \mathrm{a}$, the total number of boundaries identified through each technique were counted and separated into their respective misorientation intervals. Figures $8 \mathrm{~b}$ and $9 \mathrm{~b}$ represent the number fraction of the boundaries in each interval and was determined by dividing the number of boundaries in each interval found in Figures 8a and 9a by the total number of boundaries identified. For the thixocast samples, the number and fraction of grain boundaries using both color metallography and EBSD follow each other closely and have the same trend. In general, the EBSD technique detects more boundaries than color metallography. This is evident in the graph for the number of identified boundaries (Figures $8 a$ and 9a). However, the fraction graphs support the idea that we could definitely rely on the results of the color metallography as the trend is similar.

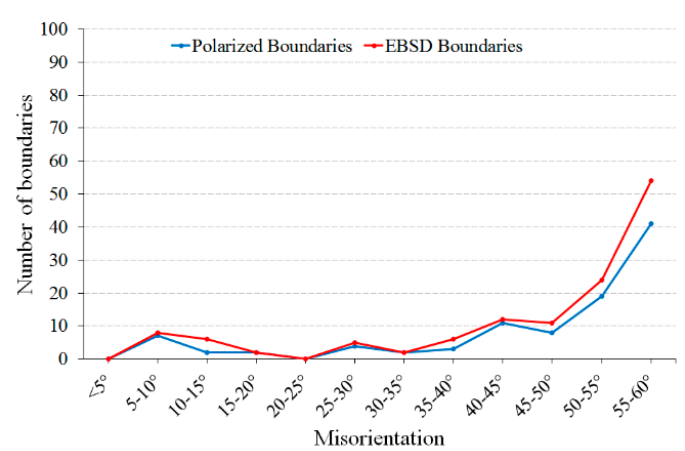

(a)

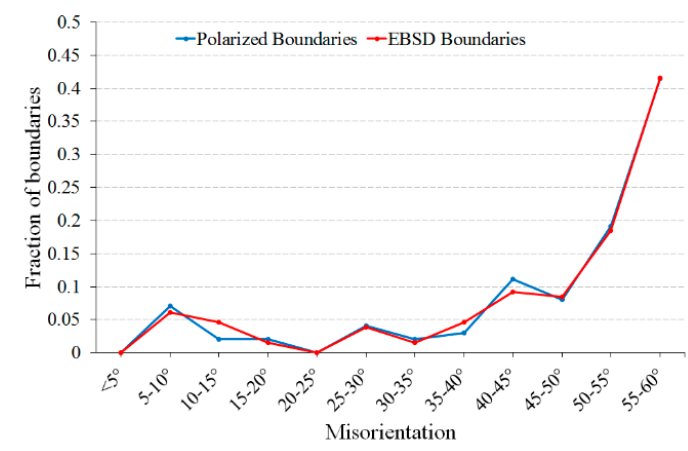

(b)

Figure 8. Number of identified boundaries (a) and fraction of boundaries (b) based on the misorientation angles, thixocast sample. 


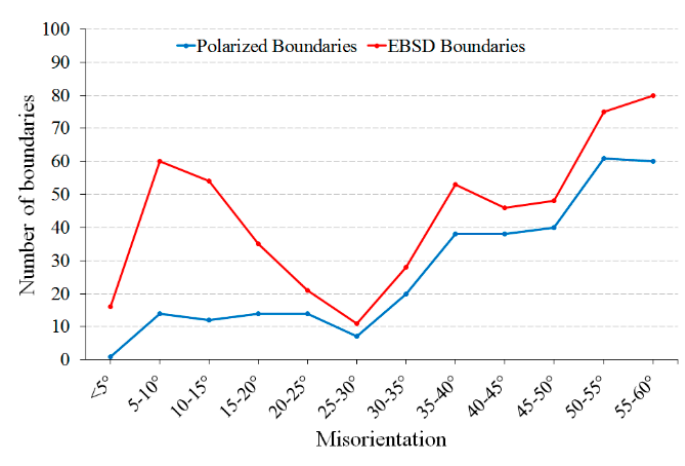

(a)

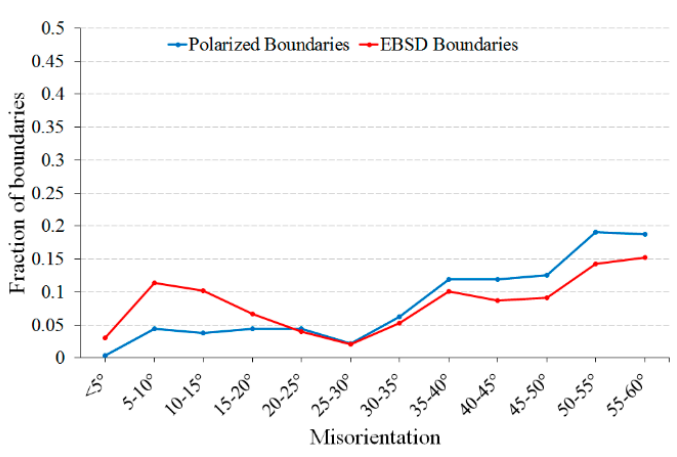

(b)

Figure 9. Number of identified boundaries (a) and fraction of boundaries (b) based on the misorientation angles, as-cast EMS billets, sand mold billets.

In the case of as-cast EMS sand billets, the number and fraction of grain boundaries in both color metallography and EBSD follow each other closely and have the same trend. However, comparing Figures 8 and 9, the difference between color metallography and EBSD results in as-cast EMS samples are more than the thixocast samples. This is due to the color distinction in these samples. EBSD is more accurate for samples having complications during color metallography and EBSD detects far more boundaries than were detected using polarized light and sensitive tint after anodizing. Below five degrees, color microscopy was unable to detect the difference between any boundaries as the difference in color was not significant enough to detect. Whilst EBSD did not detect any boundaries below five degrees either, this was due to the critical misorientation angle being set to five degrees and not an inherent limitation of EBSD.

When reviewing the results of grain boundary identification through color metallography and EBSD, whilst the end results were comparable, the time spent acquiring the data was significantly different. As explored in Table 1, the total time to analyze a single region with color metallography was 100 min faster than through EBSD analysis. The higher testing time associated with EBSD can be linked to the longer sample preparation time required to develop high quality scans as well as the upwards of $75 \mathrm{~min}$ required to produce a scan. Samples can be anodized and then analyzed through optical microscopy in as little as $20 \mathrm{~min}$ hence, for the time it takes to scan and analyze a single EBSD sample, four samples could be anodized and analyzed through color metallography. When comparing the cost of carrying out each technique, polishing costs are higher for EBSD than for color metallography due to the longer polishing times. Whilst this higher polishing cost is somewhat offset by the requirement of an anodizing solution, the capital expenditure and booking fees are significantly higher for an SEM than an optical microscope.

\section{Conclusions}

In order to study the capability of color metallography as a reliable microstructural characterization technique in distinguishing the primary particles, anodizing-polarized light microscopy was compared with the EBSD technique for Al-Si samples produced with different casting procedures;

1. Anodizing-polarized light microscopy combination is a reliable characterization method for microstructural analysis of as-cast alloys.

2. Color metallography is a faster and more cost-effective method for microstructural analysis of as-cast alloys, although more data is acquired through EBSD analysis.

3. It was found that a 10 degree misorientation criterion is an acceptable misorientation level for EBSD grain mapping.

4. The number and fraction of grain boundaries detected and resolved for both techniques are basically the same and have similar trend when plotted against the degree of grain misorientation. 
Author Contributions: Conceptualization, S.N.; methodology, S.N., validation, S.N. and G.V.V.; formal analysis, S.N. and A.R.; investigation, A.R.; resources, S.N. and R.G.; data curation, A.R.; writing-original draft preparation, S.N.; writing-review and editing, S.N., A.R., R.G. and G.V.V.; visualization, S.N. and A.R.; supervision, S.N.; project administration, S.N.; funding acquisition, R.G.

Funding: This research received no external funding.

Acknowledgments: The authors acknowledge the facilities, and the scientific and technical assistance, of the Australian Microscopy and Microanalysis Research Facility at Flinders University. This work was performed in part at the OptoFab node of the Australian National Fabrication Facility utilizing Commonwealth and SA State Government funding.

Conflicts of Interest: The authors declare no conflict of interest.

\section{References}

1. Nafisi, S.; Ghomashchi, R. Semi-Solid Processing of Aluminum Alloys; Springer: Berlin, Germany, 2016; ISBN 978-3-319-40333-5.

2. Niroumand, B.; Xia, K. 3D Study of the Structure of Primary Crystals in a Rheocast Al-Cu Alloy. Mater. Sci. Eng. A 2000, 283, 70-75. [CrossRef]

3. Ito, Y.; Flemings, M.C.; Cornie, J.A. Rheological Behavior and Microstructure of Al-6.5 wt \% Si Alloy. In Nature and Properties of Semi-Solid Materials; Sekhar, J.A., Dantzig, J., Eds.; TMS: Warrendale, PA, USA, 1991; pp. 3-17.

4. Suery, M. Mise en forme des alliages métalliques à l'état semi-solide; Lavoisier Publication: Paris, France, 2002.

5. Limodin, N.; Salvo, L.; Suery, M.; DiMichiel, M. In situ and real-time 3-D microtomography investigation of dendritic solidification in an Al-10 wt.\% Cu alloy. Acta Mater. 2009, 57, 2300-2310. [CrossRef]

6. Xu, W.; Ferry, M.; Mateescu, N.; Cairney, J.M.; Humphreys, F.J. Techniques for generating 3-D EBSD microstructures by FIB tomography. Mater. Charact. 2007, 58, 961-967. [CrossRef]

7. Zaafarani, Z.; Raabe, D.; Singh, R.N.; Roters, F.; Zaefferer, S. Three-dimensional investigation of the texture and microstructure below a nanoindent in a $\mathrm{Cu}$ single crystal using 3D EBSD and crystal plasticity finite element simulations. Acta Mater. 2006, 54, 1863-1876. [CrossRef]

8. Voort, G.V. Metallography, Principles and Practice; ASM International: New York, NY, USA, 1999.

9. Voort, G.V. ASM Handbook, Volume 09: Metallography and Microstructures; ASM International: Materials Park, $\mathrm{OH}, \mathrm{USA}, 2004$.

10. Oxford Instruments. Available online: www.ebsd.com (accessed on 25 April 2019).

11. OIM Analysis Tutorials, Ametek Inc. Available online: www.edax.com (accessed on 25 April 2019).

12. Vander Voort, G.F. Metallographic specimen preparation for electron backscattered diffraction. Part I. Pract. Metallogr. 2011, 48, 454-473. [CrossRef]

13. Vander Voort, G.F. Metallographic specimen preparation for electron backscattered diffraction. Part II. Pract. Metallogr. 2011, 48, 527-543.

14. Nafisi, S.; Ghomashchi, R. Microstructural Evolution of Electromagnetically Stirred Feedstock SSM Billets during Reheating Process. Metall. Microstruct. Anal. 2013, 2, 96-106. [CrossRef]

15. Flemings, M.C. Behavior of metal alloys in the semi-solid state. Metal. Trans. A 1991, 22, 952-981. [CrossRef]

16. Kirkwood, D.H. Semisolid metal processing. Int. Mater. Rev. 1994, 39, 173-189. [CrossRef]

17. Fan, Z. Semisolid metal processing. Int. Mater. Rev. 2002, 47, 49-85. [CrossRef]

18. Nafisi, S.; Emadi, D.; Shehata, M.T.; Ghomashchi, R. Effects of Electromagnetic Stirring and Superheat on the Microstructural Characteristics of Al-Si-Fe Alloy. Mater. Sci. Eng. A 2006, 432, 71-83. [CrossRef]

(C) 2019 by the authors. Licensee MDPI, Basel, Switzerland. This article is an open access article distributed under the terms and conditions of the Creative Commons Attribution (CC BY) license (http://creativecommons.org/licenses/by/4.0/). 